\title{
Los archivos eclesiásticos como fuentes para el estudio de la beneficencia en España
}

\author{
Ecclesiastical archives as sources for the study of charity in Spain
}

\section{María Guadalupe Pérez Ortiz (1), Francisco González LozAno (1), Agustín Vivas MoReno (2)}

(1) Metropolitano de San Atón de Badajoz, España, mgperort@gmail.com,fglozano@hotmail.com

(2) Universidad de Extremadura, España, aguvivas@unex.es

\begin{abstract}
Resumen
La amplísima labor desarrollada por la Iglesia católica en relación a cuestiones benéfico-asistenciales es de sobra conocida. Sin embargo, son pocos los que se detienen a observar los archivos eclesiásticos como testimonio real de estos procesos. En este artículo queremos dar prueba de ello y ofrecer pautas metodológicas que nos permitan aprovechar mejor sus ricos fondos. En particular, nos centraremos en los seminarios como entidades muy poco o nada conocidas en estas lindes pero que desarrollaron labores benéficas muy importantes, atendiendo a aquellos niños y jóvenes que necesitaban de una formación y manutención en sus centros por medio de un amplísimo sistema de becas.
\end{abstract}

Palabras clave: Archivos eclesiásticos. Archivos de seminarios. Beneficencia. Becas. Iglesia católica. España.

\section{Introducción: aproximación a la historia de la beneficencia en España}

Los estudios sobre cuestiones sociales y/o benéficas son de gran utilidad para el conocimiento de un determinado país, así como de las instituciones que abanderan este tipo de causas. La Iglesia católica desde sus orígenes tuvo muy presente al necesitado desarrollando un inmenso trabajo que hoy en día continúa. La naturaleza de la Iglesia nos permite observar cómo las cuestiones sociales y muy especialmente las relacionadas con la beneficencia, en el más amplio sentido de la palabra, han sido promovidas y ejecutadas desde diferentes eslabones dentro de la jerarquía eclesiástica: parroquias, conventos, órdenes religiosas, hospitales, asilos, orfanatos, seminarios, etc. En nuestra investigación queremos dar prueba de ello por medio de un aspecto concreto: la atención a las cuestiones de carácter social que reflejan los archivos eclesiásticos. Aún delimitado el tema a las cuestiones estrictamente benéfico-archivísticas, el marco de trabajo seguiría siendo amplísimo dado que la Iglesia ha desarrollado una importantísima actividad en este sentido. Por ello,

\begin{abstract}
The work carried out by the Catholic Church over the centuries in relation to caring issues is well known. However, few people are aware of Church records as a real testimony of these processes. In this article we want to give proof of this reality, trying to offer methodological guidelines to profit from the its rich archives. In particular, we will focus on seminars because of their role in providing support for children and young people through a vast system of scholarships and training.
\end{abstract}

Keywords: Ecclesiastical archives. Seminar archives. Charities. Scholarships. Social history. Catholic church. Spain.

nos centraremos en una de las menos conocidas actividades benéficas desarrolladas por esta institución, la relacionada con cuestiones benéficoeducativas en archivos eclesiásticos, especialmente en los archivos de seminarios.

La Iglesia, siempre promotora de cultura, ha trabajado incesantemente en el desarrollo de la misma, pero muy especialmente en el acercamiento de la educación a los más desfavorecidos. Los seminarios como entidades eclesiásticas educativas son uno de los principales promotores de estas cuestiones. No olvidemos que su misión fundamental es la formación integral de los que van a ser pastores de la Iglesia. Sus archivos son por tanto foco de contenidos educativos. El análisis de su documentación nos permite observar cómo desarrollaron un amplio sistema de ayudas a la educación de los más necesitados que permitió que muchos niños y jóvenes españoles de todos los tiempos pudieran recibir una pertinente formación.

En líneas generales y tratando el tema de la beneficencia en España desde un mero carácter introductorio y dado la amplísima bibliografía que 
existe al respecto, nos limitaremos en este apartado a exponer unas breves pinceladas sobre la cuestión que permitan al lector situarse dentro de un contexto (Asociación Archiveros de la Iglesia, 1995; Barrada, 2001; Borrel, 2007; Carasa, 1998, 2004; Jiménez, 1972; Cardona, 2005; Casado, 2003; Comín, 2010; Fernández, 2007; García, 1996; Herrera, 1999; Maza, 1987; Maza, 1999; Palma, 2006; Posada, 1995; Uribe, 2006; Vives, 2000). El dato más antiguo sobre beneficencia en España se remonta (Sánchez, 1869) a 1438, en cuyo año y con motivo de una gran epidemia, se fundó un hospital en Madrid que se dedicó al socorro de los contagiados.

Para comprender el papel que desempeñaron estas instituciones, especialmente en sus primeras etapas nos será muy útil entender el sentido reverencial de la pobreza en la mentalidad cristiana desde la Edad Media, para la cual el pobre era testimonio de la vida de Cristo. El cambio de mentalidad sobre el vagabundismo surge en el siglo XIV debido a la aparición de nuevos imperativos económicos y sociales. Entonces se tacha la pobreza de vicio y la vagancia de delito. Se producen las terribles epidemias de peste negra, la proliferación de pobres y vagabundos, niños expósitos, pícaros, etc. Todo ello explica el elevado número de centros asistenciales que se constituyen en España durante los siglos XV y $\mathrm{XVI}$ gestionados por la Iglesia católica.

Las primeras leyes de beneficencia de España se remontan al año 1528 (Alemán y Fernández, 2004; Maza Zorrilla, 1987). Durante el siglo XVI fueron muchos los colegios, inclusas, asilos y hospitales que se fundaron por todo el mundo. Esta incesante actividad benéfica entra en un lento proceso de decadencia a partir del siglo XVII. Muchas eran las instituciones y escasas las dotaciones que existían, por lo que algunos hospitales se vieron obligados en el siglo XVIII ha refundirse con otros. Nos situamos en una época que podría ser definida como de relajación del espíritu religioso y donde, además, la asistencia pública adquiere un carácter social del que carecía hasta la fecha y se convierte en obligación del Estado. La acometida desamortizadora de 1798 ordena enajenar los bienes de hospitales, cofradías, etc., continuando progresivamente con otras leyes (Cruz Arias, 1987). La pobreza comienza a ser un problema que tiene que ser asimilado desde el Estado. La Ley General de Beneficencia de 1822, el ordenamiento legal de la pobreza y la mendicidad, en los albores del Liberalismo, apuestan por la previsión frente a las medidas coercitivas de resonancias dieciochescas. Poco tiempo después, el Código Penal de 1850 reprime la mendicidad. El Código Penal de 1870, vigente hasta bien avanzado el siglo $X X$, no se pronuncia sobre la mendicidad, lo que significará que su control futuro se hará por medio de leyes específicas y disposiciones concretas (Maza, 1999).

\section{Aproximación a las fuentes de información}

Como ya hemos señalado en el apartado anterior la atención al necesitado en España ha sido llevada a término desde diferentes sectores según el momento histórico en el que nos situamos. En líneas generales, dado que no es la base fundamental de esta investigación, para la localización de contenidos de carácter benéfico-asistenciales los usuarios pueden acceder a diversas fuentes archivísticas:

Archivos Civiles. Como hemos referido en el apartado anterior desde el siglo XIV el Estado asume el control de la beneficencia en nuestro país. Es en este momento cuando aparece una interesante documentación al respecto que en muchos casos es de carácter puramente normativo pero que nos permite comprender el cambio de mentalidad de la época así como los procedimientos llevados a término en esta importante cuestión. Recurriremos por tanto a los archivos civiles si queremos acercarnos principalmente al sistema legislativo que desde el Gobierno español se desarrolló para dar control a las cuestiones benéficas, así como a la documentación generada por las entidades constituidas por el Estado para el desarrollo de estas tareas; en sus archivos además de su documentación fundacional e histórica localizaremos los expedientes de usuarios de estos servicios.

Archivos Eclesiásticos. Al referirnos a este tipo de archivos debemos delimitar muy bien las instituciones que dentro de la Iglesia se encargaron de estas tareas. Principalmente fueron las parroquias, las órdenes religiosas de vida activa, las instituciones benéficas propiamente dichas (asilos, hospitales y orfanatos) y los seminarios. En ellos, como veremos en los sucesivos apartados de esta investigación, localizaremos una amplísima documentación que nos permitirá el conocimiento histórico de la institución, la gestión de su patrimonio, si lo hubiere, y los expedientes de los usuarios de dichas entidades.

\section{Hipótesis de trabajo y objetivos}

La investigación pretende acercar al lector a las labores benéfico-asistenciales realizadas por la Iglesia a lo largo de los tiempos, de forma particular ciñéndose a dichas cuestiones en los seminarios y para ello, tomando como base el análisis de los documentos contenidos en sus archivos. Nuestro objetivo fundamental será presentar los 
archivos de seminarios como entidades que custodian un importante volumen de documentación de carácter benéfico, especialmente en su vertiente educativa, centrándonos en la exposición de un cuadro de clasificación marco sobre archivos de seminarios; el desarrollo específico de secciones y series documentales donde se da cabida la documentación que generan estas entidades en relación a aspectos benéfico-educativos, y la exposición de otros cuadros de clasificación de archivos eclesiásticos que desarrollan dichas cuestiones para que el lector pueda establecer comparativas con los archivos de seminarios.

\section{Archivos eclesiásticos: secciones y series documentales relacionadas con la beneficencia}

La Iglesia ha asumido a lo largo de su existencia la asistencia al más necesitado. Este hecho conlleva que las diferentes estructuras que componen la Iglesia trabajen en cuestiones relacionadas con la beneficencia. Descendiendo de un modo particular a los aspectos que más nos interesan en nuestra investigación podamos observar como varios cuadros de clasificación de archivos eclesiásticos albergan, en mayor o menor medida, contenidos relativos a esta cuestión. Sin lugar a duda son los archivos de beneficencia los que aportan mayor volumen de contenidos al contexto, pero existen otros archivos donde también aparecen. Por tanto, procederemos ahora a establecer un breve análisis de los cuadros de clasificación de archivos eclesiásticos que contienen secciones o series documentales dedicadas a las cuestiones benéficas; dejando al margen los archivos de seminarios, que como base de esta investigación, serán abordados en un apartado independiente.

\subsection{Archivos parroquiales}

El cuadro de clasificación que se aplica, en líneas generales, para los archivos parroquiales aparece divido en seis grandes secciones que corresponden a las principales funciones y competencias con las que podemos identificar a las parroquias: Administración, Fondos Musicales, Gobierno, Instituciones Parroquiales, Organismos Supra-parroquiales y Sacramentales.

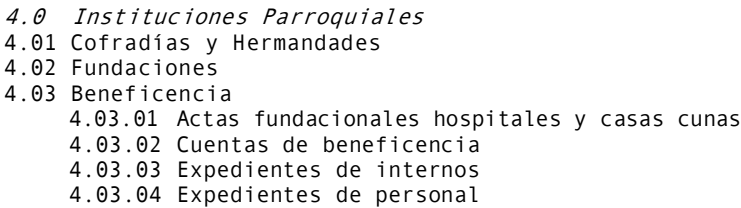

Figura 1. Sección de Instituciones parroquiales
Dentro de la sección dedicada a Instituciones $\mathrm{Pa}$ rroquiales es donde se ubica la documentación relacionada con la labor asistencial o benéfica desarrollada desde las parroquias. La sección Instituciones Parroquiales (4.0) da cabida a los fondos generados por entidades que sin ser propiamente parroquia tienen su sede en ella; son conocidas como instituciones vinculadas. La estructura de esta sección dependerá de cada caso. Nos centraremos en la relativa a beneficencia, la subsección Beneficiencia (4.03), que abarca la documentación producida por entidades dedicadas a la beneficencia de las que la parroquia era gestora o al menos encargada de su supervisión. El cuadro de clasificación será adaptado a cada caso. Por lo general, dos eran las principales instituciones dedicadas a la beneficencia que guardaban relación directa con las parroquias: hospitales y casas cunas.

La serie de actas fundacionales de hospitales y casas cunas hace relación al proceso por la que un hospital o casa cuna queda constituido. Dado que estas entidades carecían de archivo propio, este primer documento suele custodiarse en los parroquiales. La serie de Cuentas de beneficencia (4.03.02) procede de una tarea desarrollada, en la gran mayoría de casos, desde las parroquias, si bien es cierto que las cuentas siempre han sido independientes. La serie de Expedientes de internos incluye documentación sobre las personas que en calidad de enfermos o como integrantes de las casas cunas, formaron parte de estas entidades. Finalmente, los Expedientes de personal son la documentación del personal que prestó sus servicios a estas entidades.

\subsection{Archivos de órdenes religiosas} de vida activa

El cuadro de clasificación que se aplica, en líneas generales, para los archivos de órdenes religiosas de vida activa aparece divido en cuatro secciones que corresponden a las principales funciones y competencias con las que podemos identificar estas entidades: Administración, Gobierno, Justicia y Oficios. Dentro de esta última sección dedicada a Oficios es donde se ubica la documentación relacionada con la labor asistencial o benéfica desarrollada desde las instituciones religiosas de vida activa.

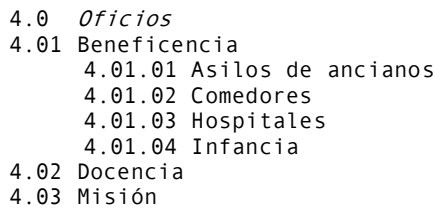

Figura 2. Sección de Oficios 
La sección Oficios (4) alberga la documentación que hace referencia a las competencias particulares de cada una de estas entidades. Por ello, el cuadro de clasificación deberá ajustarse a estas tareas siendo prescindible aquellas partes que no se relacionen con sus competencias particulares. La primera subsección Beneficencia (4.01), aparecerá en aquellos institutos dedicados a la atención de asilos, hospitales, orfanatos, etc. Es de gran interés a la hora de estudiar la asistencia social a los marginados, la sanidad, al mismo tiempo que nos permite redactar estadísticas fiables sobre el número y procedencia geográfica de los acogidos en residencias, asilos, etc. Se dividirá en tantas subsecciones como competencias tengan atribuidas estas entidades. La estructura más usual es la que se divide es en asilos, comedores, hospitales e infancia.

\subsection{Archivos de beneficencia}

Los cuadros de clasificación de estas entidades recogen a lo largo de toda su estructura documentos relacionados con las labores benéficas y asistenciales desarrolladas por la Iglesia católica en sus diferentes competencias. Por ello, son expuestos a continuación para que el lector pueda comprender la documentación generada en función a la competencia que desarrollan.

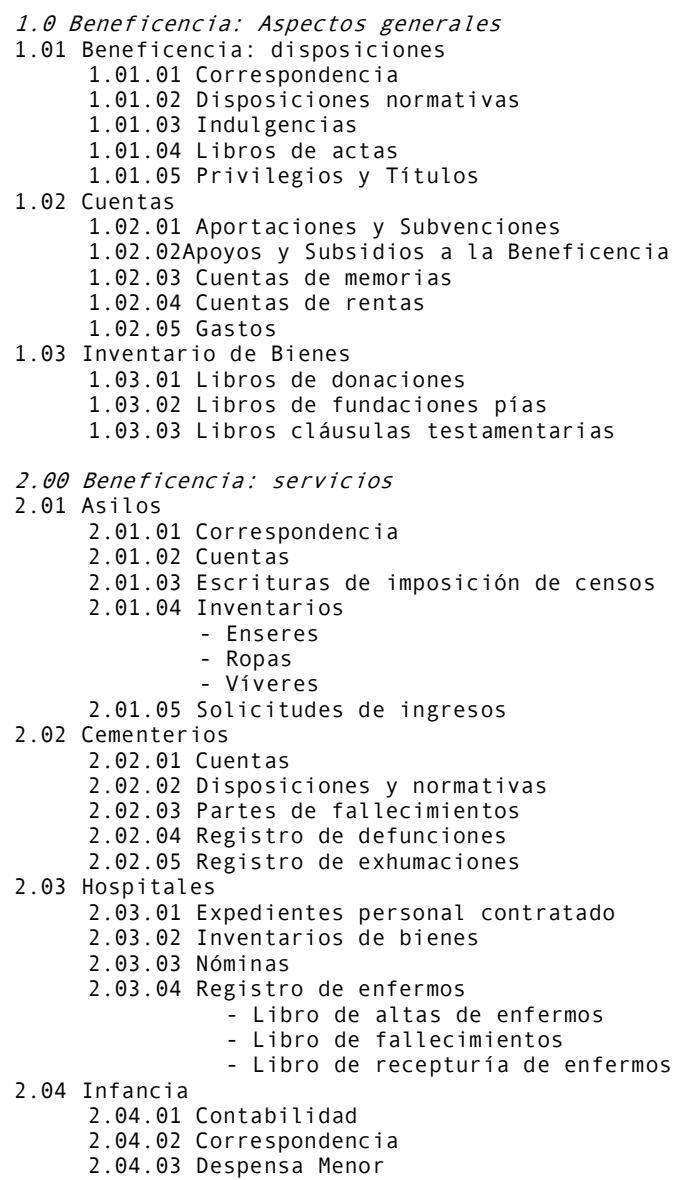

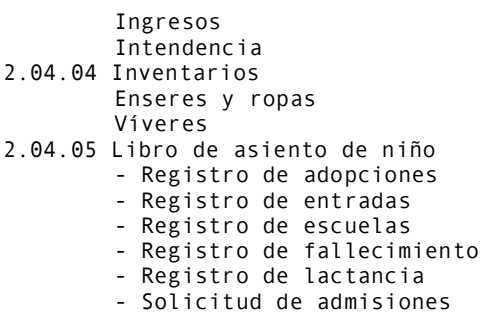

Figura 3. Sección de Beneficiencia

1. Beneficencia: aspectos generales. Como su nombre indica en esta primera sección se dará cabida la documentación más general que abarca aspectos sumamente dispares con relación a estas entidades. Se estructura en tres subsecciones.

La primera subsección, Beneficencia: disposiciones, abarca aquella documentación de carácter dispositivo que tiene la misión de enseñar o notificar algo. Se presenta dividida en cinco series documentales:

- Correspondencia: documentación en la que se establece comunicación directa entre entidades de beneficencia y otras instituciones con el fin de dar a conocer algo.

- Disposiciones normativas: las entidades eclesiásticas de rango superior, sirva de ejemplo el obispado, mantenían comunicación constante con estas instituciones con el fin de controlar su funcionamiento.

- Indulgencias: son documentos en los que se obtiene por parte de la alta jerarquía de la Iglesia una remisión de la pena temporal de pecados que ya han sido perdonados.

- Libros de actas: documentación que hace referencia a los acuerdos que se llevaron a término en el momento en que se fundan las instituciones de beneficencia, así como a otros que se toman en el desarrollo de la propia entidad.

- Privilegios y Títulos: documentación en la que se reflejan ventajas o beneficios concedidos a estas instituciones o en la que se otorga o reconoce un derecho u obligación.

La segunda subsección 1.02 Cuentas está dedicada a la documentación contable que nace de ciertos procesos bajo los que estas entidades se desarrollan. Queda estructurada en

- Aportaciones y Subvenciones: documentación que acredita los ingresos que llegan a las entidades de beneficencia gracias a aportaciones económicas específicas. 
- Apoyos y Subsidios a la Beneficencia: los apoyos a la beneficencia fueron sumamente comunes en otras épocas. Instituciones civiles y también otras entidades eclesiásticas dotaban a las benéficas de medios económicos para poder atender a sus múltiples necesidades.

- Cuentas de memorias: son cuentas desarrolladas por estas entidades con el fin de justificar la forma en la que se emplean los ingresos.

- Cuentas de rentas: como su nombre indica se desarrollaban unas cuentas especificas en las que registraban los ingresos que provenían de esta vía.

- Gastos: se trata de una relación detallada en la que se específica el uso de los ingresos con los que la entidad benéfica contaba para su funcionamiento diario.

La subsección Inventario de bienes (1.03) incluye:

- Libros de donaciones: registro en el que anotan todos los bienes que han llegado a la entidad bajo esta vía. Su estudio nos permite observar como el número de donaciones desciende significativamente si lo comparamos con otras entidades religiosas.

- Libros de fundaciones: registro en el que anotan los bienes que han llegado a la entidad por medio de estas instituciones. Su volumen es considerablemente menor si lo comparamos con otras entidades eclesiásticas. Sirvan de ejemplo, conventos y monasterios.

- Libros cláusulas testamentarias: registro en el que anotan los bienes que han llegado a la entidad gracias a las últimas voluntades de personas. Su análisis nos permitirá observar cómo el número de personas que en sus testamentos citan como beneficiarias estas entidades es sumamente reducido.

La segunda subsección 2. Beneficencia: servicios es de suma importancia, dado que en ella aparecerán cada una de las tareas que las entidades benéficas desempeñan, dando lugar a una documentación específica:

- Asilos: una de las tareas principales a las que se dedicaban las entidades benéficas era la atención de los ancianos por medio de los asilos. Encontramos cinco series documentales, aunque pudieran establecerse algunas más:

-Correspondencia: comunicación específica de estas entidades con otras entidades o viceversa. Son de sumo interés aquellos informes en los que las entidades benéficas dan fe al obispado de la forma de empleo de sus recursos o de las limitaciones y carencias por las que atraviesan.

-Cuentas: diario económico de estas entidades en los que quedan registrados los movimientos económicos (gastos e ingresos) que efectuaban y la periodicidad de los mismos.

-Escrituras de imposición de censos: en la antigüedad no era inusual que estas entidades fueran beneficiadas por ciertos censos. Toda la documentación referida a los mismos es la que se ubica en esta serie documental.

- Inventarios: registros en los que se especifican los diferentes tipos de bienes con los que estas entidades disponían.

- Solicitudes de ingreso: se trata de la documentación que los internos debían aportar para ser valorados e incorporados o no a la entidad benéfica.

- Cementerios, en la antigüedad ciertas entidades benéficas se encargaban de la gestión de los cementerios.

-Cuentas: como cualquier institución su funcionamiento genera una serie de gastos e ingresos que dan lugar a esta serie documental.

-Disposiciones y normativas: es interesante observar como desde el obispado y desde algunas instituciones civiles se imponen ciertos condicionantes a las entidades benéficas para la gestión de los cementerios.

-Partes de fallecimiento: no podía faltar esta serie documental en la que se recopila toda la documentación que certifica la muerte de una persona.

-Registro de defunciones: es el libro en el que se anota la persona y la fecha en el que se produce el fallecimiento. Su estudio puede ser de utilidad para investigaciones de carácter sociológico y demográfico.

- Registro de exhumaciones: debía existir un libro específico para esta particular circunstancia, en el que además de la los datos que aparecen el libro de defunción se anota la causa y la fecha de la exhumación.

- Hospitales. La labor de asistencia al enfermo es por antonomasia la tarea que ha caracterizado a las entidades benéficas:

-Expedientes de personal contratado: como su nombre indica es la documentación que 
de cada persona que presta un servicio remunerado al hospital se conserva en el archivo.

— Inventarios de bienes: al igual que en otras instituciones benéficas, los hospitales inventariaban sus bienes. Estos registros permitían conocer a las entidades hasta qué punto podían extender su labor asistencial.

- Nóminas: documentación referida a los pagos del personal asalariado en los hospitales.

—Registro de enfermo: es la serie documental más amplia y a la vez más significativa dado que en ella se da cabida a la documentación que específicamente tiene que ver con la labor hospitalaria. Así, podemos encontrar registros de entrada de enfermos, informes de tratamientos, registros de altas o fallecimientos, etc.

- La cuarta subsección es la relativa a la infancia, dado que la asistencia a los niños ha sido también otra de las grandes tareas encomendadas a estas instituciones a lo largo de los tiempos. Se divide en cinco series:

- Contabilidad: como en el resto de casos es la documentación que da fe de los gastos e ingresos que estas entidades mantienen para su desarrollo.

- Correspondencia: comunicación específica de estas entidades con otras entidades o viceversa.

-Despensa menor: esta serie documental hace alusión a la intendencia con la que las entidades contaban.

- Inventarios: al igual que en otras instituciones benéficas, los centros de atención a la infancia inventariaban sus bienes. De este modo aparecen libros de registros en los que se contabilizan los enseres y otros útiles, así como la ropa que dispone la institución y la vía por la que ha llegado a la misma. En algunos libros de registro se anota la distribución de estos recursos para poder dar muestra de su uso.

- Libro de asiento de niños: es sin lugar a duda la serie documental más importante dado que en ella se recopila la información básica para entender la forma en la que estas entidades desarrollaban sus tareas. Cada uno de estos procedimientos generaba una documentación específica. Así podemos encontrar los registros de adopciones, o de fallecimientos de menores, las solicitudes para ser admitidos en estos centros, etc.

\section{Los seminarios y la beneficencia: los archivos de seminarios testigos de la labor social de estas entidades}

El Concilio de Trento cerró un período de notables irregularidades en la gestión temporal de la Iglesia y en la formación de los presbíteros, e inició una etapa de claridad doctrinal, de disciplina y centralización que culminaría siglos después en el Concilio Vaticano II.

A tenor del decreto De Seminariorum erectione et regimine, de 15 de julio de 1563, se dictaminó la creación en todas las diócesis de seminarios. El nacimiento de una nueva institución orientada a la formación de los clérigos nos conduce directamente a la situación de la Iglesia católica en un periodo de confusión doctrinal. Las graves carencias formativas de la Iglesia aquejaban a la misma clerecía. Y así, urgía la implantación de seminarios que llevaran a cabo esta misión (Vergara, 1996). Se presentaba así esta institución como un internado, con enseñanza especial y disciplina particular, siguiendo unos actos de piedad propios de candidatos a órdenes sagradas, bajo la autoridad del obispo, representado en la figura del rector (Rops, 1970).

La misión fundamental de los seminarios fue aclarada desde el principio: la educación de los niños y jóvenes que aspiraban a la clerecía. Ahora bien, dentro del amplísimo plantel de alumnos que se acercaron a los seminarios, no todos recibieron el sacramento del Orden, aunque sí fueron receptores de una especial impronta que entre otros pilares se sustentaba en la promoción cultural y educativa. Las realidades económicas que marcaban a las familias de estos jóvenes fueron muy dispares. Muchos de ellos de escasos recursos económicos pudieron recibir una sólida formación personal, doctrinal y educativa gracias a la inmensa labor benéfico-educativa realizada por estas instituciones a través de un interesante programa de becas que los seminarios desarrollaron para que sus alumnos más pobres pudieran permanecer en ellos. Las becas a las que optaban los seminaristas requerían de ciertas condiciones, acreditar pobreza y conducta intachable pueden resumir estos requisitos. Pero a cambio permitían estudios y hospedaje gratuito, o parcialmente gratuitos dependiendo del tipo de beca a la que se optara. Los obispos fueron grandes promotores de las mismas y no olvidaron potenciarlas en sus seminarios.

Incluso en algunos seminarios, sirva de ejemplo el de la ciudad de Badajoz, se desarrolló una sección específica (Sección San Sisenando del 
Seminario San Atón) destinada a los seminaristas más pobres debido fundamentalmente al amplio número de solicitudes que llegaban a este centro (González Lozano, 2015). Los seminaristas de esta sección ocupaban las plazas de fámulos y eran los encargados de desarrollar tareas de limpieza en el centro pero a cambio recibían manutención y formación gratuita permitiéndoles desarrollar su vocación sacerdotal que sería acompañada de una sólida formación educativa.

Veamos en este momento los contenidos sobre cuestiones benéfico-educativas, que como hemos señalado en los seminarios se desarrollaron fundamentalmente por medio del sistema de becas, y que aparecen reflejados en sus cuadros de clasificación archivísticos (Figura 4).

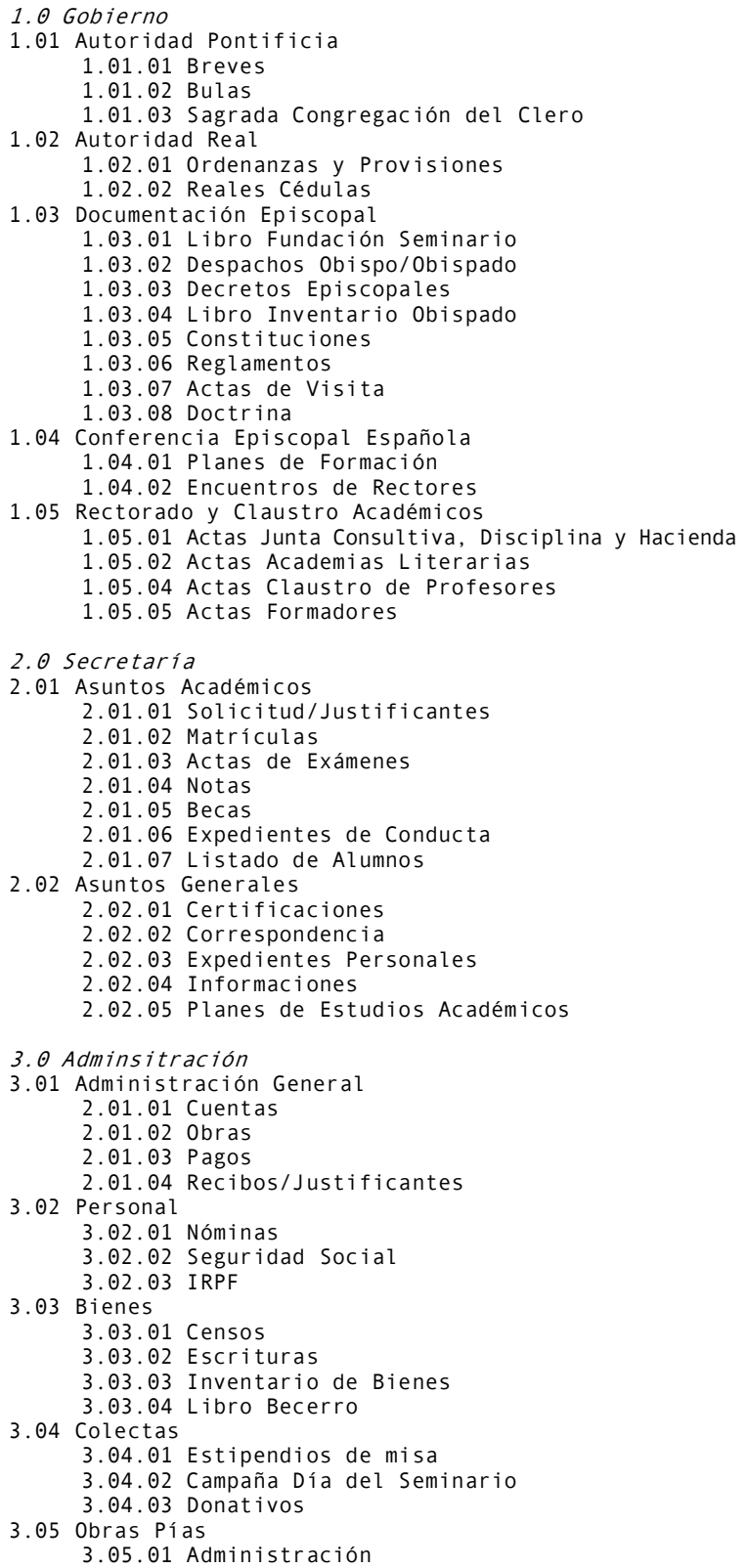

3.05.02 Cuentas

$$
\text { - Inventario de Bienes }
$$

3.05.02 0bras Pías

4.๑ Órdenes sagradas

4.01 Expedientes de órdenes

Figura 4. Propuesta de cuadro de clasificación tipo para archivos de seminarios

Dentro de los cuadros de clasificación que constituyen los archivos de seminarios podemos extraer cuestiones relativas a la labor benéfica desarrollada por la Iglesia por medio de estas instituciones principalmente en dos grandes secciones: secretaría y administración. Vamos a examinar las series más importantes dentro de dichas secciones.

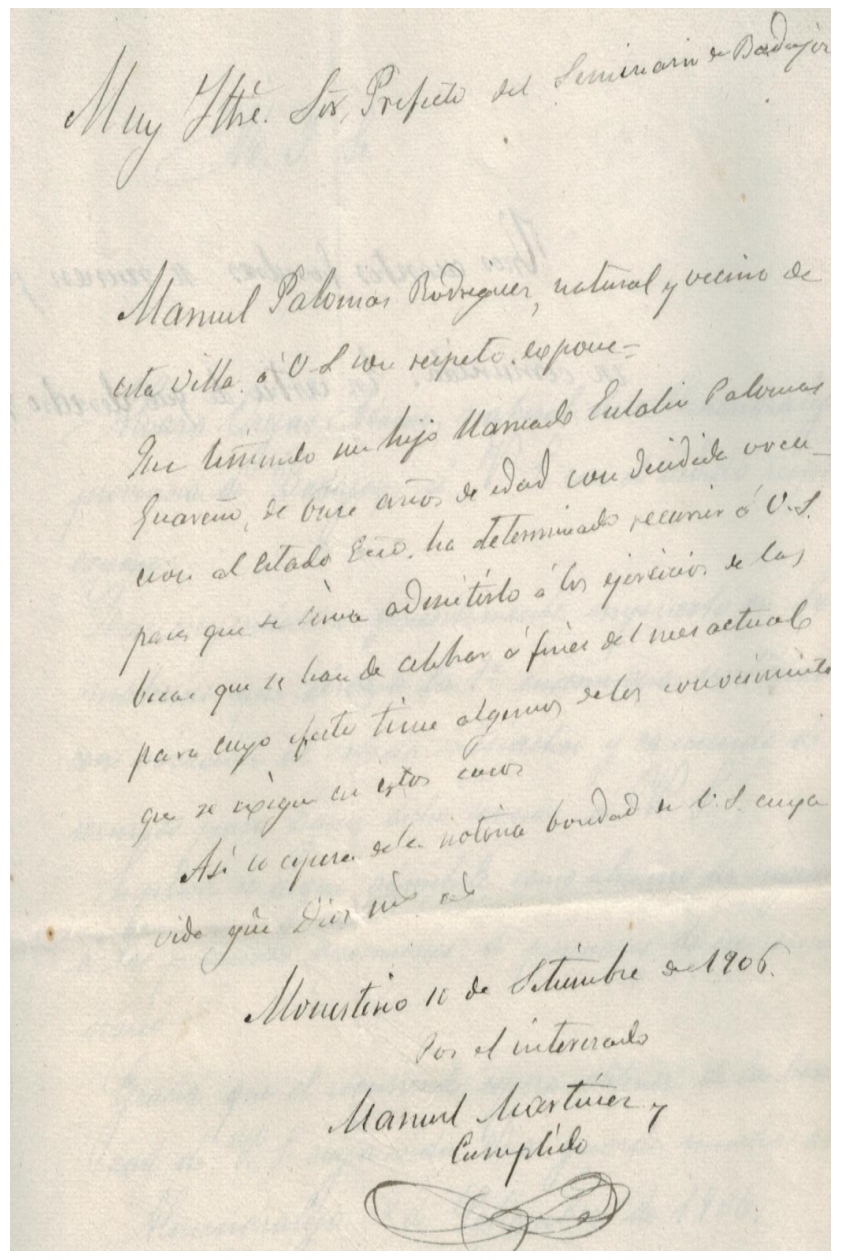

Figura 4. Solicitud para la concesión de beca en el Seminario Metropolitano San Atón de Badajoz (A.S.M.M.B. Sección secretaría, caja 62)

Dentro de la Sección Secretaría destacan las Solicitudes y Justificantes. La solicitud es el primer paso que el seminarista debía emprender para iniciar sus estudios en un seminario. Los alumnos que deseaban ingresar debían enviar al 
obispo o al rector, una súplica o petición informando de los deseos que le llevaban a querer ingresar en este centro. No debemos olvidar que se trata de una entidad donde se iban a formar los futuros sacerdotes y esta cuestión debía ser la base fundamental del documento. En estos documentos se incluye además de los deseos vocacionales, información detallada del alumno y de sus progenitores, así como de su procedencia, que nos permitirán trazar interesantes estudios estadísticos; contenidos relativos a la pobreza del candidato, solicitando ya desde este momento la posibilidad de optar a beca o exención del pago de matrícula.

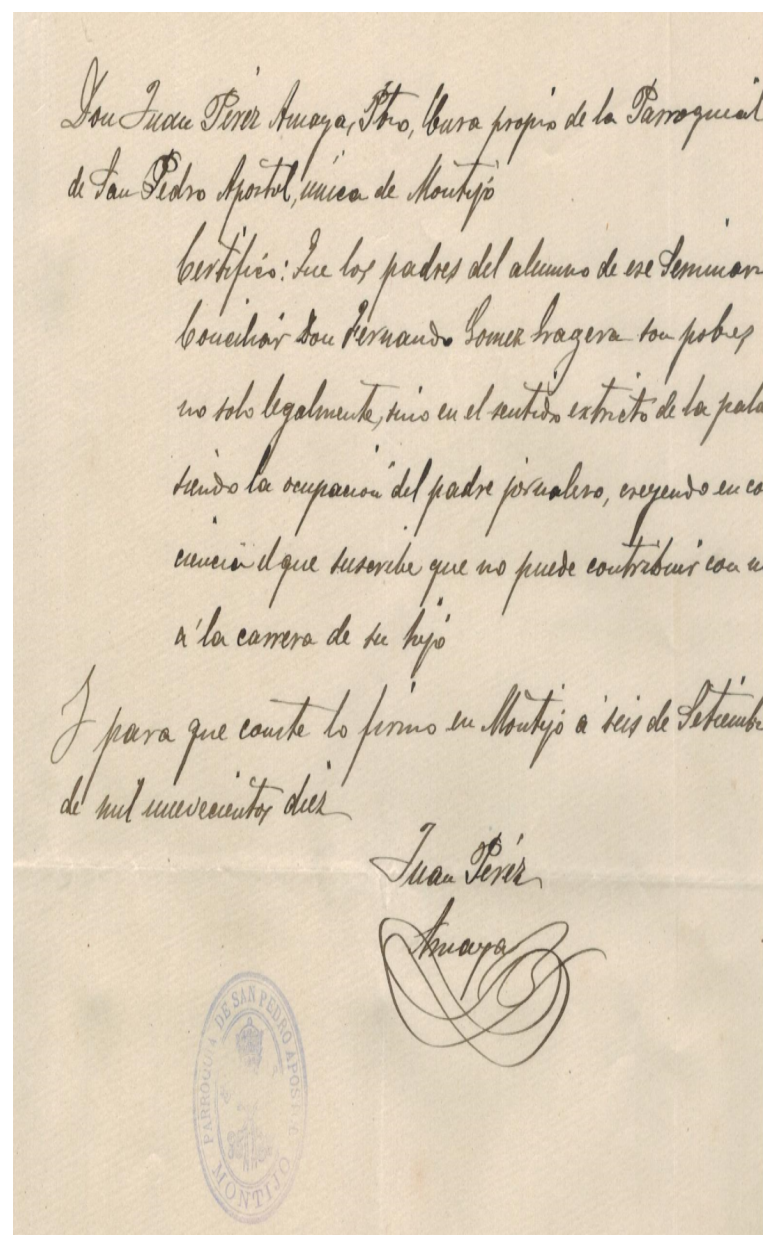

Figura 4. Certificado de pobreza de un seminarista (A.S.M.M.B. Sección Secretaría, caja 62)

Por su parte, las becas hacen alusión a las ayudas económicas que se concedían para que los seminaristas pobres o con menos recursos pudieran realizar estudios en los seminarios. Integra de dos series documentales:

- Adjudicaciones de becas: documentos en los que se hace constar la persona a la que se le ha concedido una beca, así como la cuantía de la misma. En la mayoría de los casos se les eximía del pago de la matrícula.

- Solicitudes de becas: documentos en los que se reclama ser el benefactor de una ayuda económica para poder cursar estudios en estos centros acreditando la falta de recursos.

Finalmente, la documentación relativa a la sección Administración nos permite observar en profundidad el amplio sistema de becas que se desarrolla en cada centro dado que en dichos documentos podemos analizar los candidatos que optaron a las mismas, así como el tipo de beca del que pudieron disfrutar pudiendo así emprender sus estudios y formación. En base al análisis exhaustivo de esta documentación podemos afirmar como los seminarios fueron también entidades que promovieron la ayuda al necesitado.

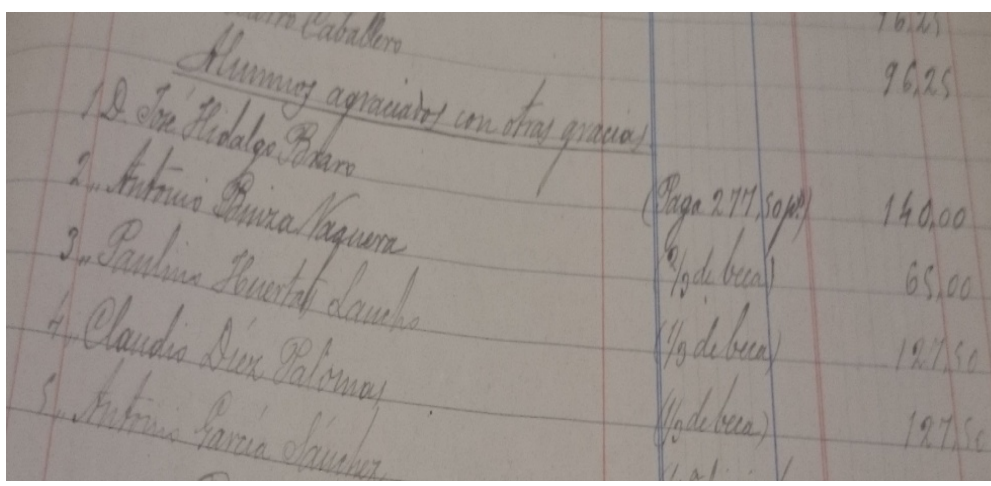

Figura 3. Anotaciones en libros de cuentas sobre exenciones de pagos. (A.S.M.M.B. Sección administración, libro 85)

\begin{tabular}{|c|c|c|}
\hline Archivos & $\begin{array}{l}\text { Secciones/ } \\
\text { Subsecciones }\end{array}$ & Series \\
\hline Parroquiales & $\begin{array}{l}\text { Instituciones } \\
\text { Parroquiales/ } \\
\text { Beneficencia }\end{array}$ & $\begin{array}{l}\text { Actas } \\
\text { fundacionales } \\
\text { hospitales y casas } \\
\text { cunas } \\
\text { Cuentas de } \\
\text { beneficencia } \\
\text { Expedientes de } \\
\text { internos } \\
\text { Expedientes de } \\
\text { personal }\end{array}$ \\
\hline $\begin{array}{l}\text { Órd. Vida } \\
\text { activa }\end{array}$ & $\begin{array}{l}\text { Oficios/ } \\
\text { Beneficencia }\end{array}$ & $\begin{array}{l}\text { Asilos de ancianos } \\
\text { Comedores } \\
\text { Hospitales } \\
\text { Infancia }\end{array}$ \\
\hline Beneficencia & Completo & Completo \\
\hline \multirow[t]{2}{*}{ Seminarios } & $\begin{array}{l}\text { Administración/ } \\
\text { Administración } \\
\text { general }\end{array}$ & $\begin{array}{l}\text { Recibos } \\
\text { Justificantes }\end{array}$ \\
\hline & $\begin{array}{l}\text { Secretaría/ } \\
\text { Asuntos } \\
\text { Académicos }\end{array}$ & $\begin{array}{l}\text { Solicitudes } \\
\text { Justificantes } \\
\text { Becas }\end{array}$ \\
\hline
\end{tabular}

Tabla I. Archivos eclesiásticos y contenidos benéficos 
Como han podido observar a lo largo de este cuarto epígrafe, los contenidos susceptibles de formar parte de investigaciones de tipo benéfico provenientes de los archivos de la Iglesia son muy variados apareciendo reflejados en un nutrido conjunto de archivos eclesiásticos, que se resumen en la Tabla I.

\section{Conclusiones}

Partiendo de la documentación conservada en archivos eclesiásticos podemos afirmar la amplísima labor desarrollada por la Iglesia católica en cuestiones benéficas y asistenciales. Tomando como base la documentación que albergan los archivos de seminarios afirmamos el papel de estas entidades como promotores de educación y cultura, atendiendo siempre a los más desfavorecidos con un amplísimo sistema de becas y ayudas que posibilitaron la formación de todo tipo de alumnos.

El importante papel que desempeñan los archivos eclesiásticos, especialmente parroquiales, de órdenes de vida activa, de beneficencia y de seminarios, para la reconstrucción de la historia de estas entidades, del proceso benéfico en nuestro país, así como de las personas que un momento determinado utilizaron de dichos servicios; en definitiva como fuente fundamental para la memoria histórica en estas lindes.

El testimonio vital que transmiten los archivos de la Iglesia, especialmente los de seminarios, para dar a conocer labores benéficas concretas. En este caso, relacionadas con la educación.

En resumen, los archivos eclesiásticos son vitales para el trazado de la historia de la beneficencia en nuestro país fundamentalmente debido a su antigüedad y a su continuidad en el tiempo. No sólo los registros parroquiales contienen datos de utilidad para estos estudios. Como ya hemos visto los usuarios deben acceder a otros archivos eclesiásticos tales como de órdenes de vida activa, de beneficencia y de seminarios, para completar sus investigaciones.

\section{Referencias}

Alemán Bracho, M.C. y Fernández García, T. (2004). Introducción a los servicios sociales. Madrid: Universidad Nacional de Educación a Distancia, 2004.

Asociación de Archiveros de la Iglesia en España (1995). Beneficencia y Hospitalidad en los Archivos de la Iglesia en España. // Memoria Ecclesiae X-XI (1995).

Barrada, A. (2001). La protección social en España hacia 1845. Bilbao: Fundación Banco Bilbao Vizcaya, 2001.

Borrel, M. (2007). Hospicis i hospitals de pobres. Girona: Diputació, 2007.
Carasa, P. (1988). Crisis del Antiguo Régimen y acción social en Castilla. León: Junta de Castilla y León, 1988.

Carasa, P. (2004). Beneficencia y cuestión social. Bilbao: Universidad del País Vasco, 2004.

Cardona, A. (2005). La salud pública en España durante el Trienio Liberal. Madrid: CSIC, 2005.

Carta circular de la Nunciatura Apostólica en España a los Reverendísimos Prelados sobre la reorganización de los archivos eclesiásticos (1929). // Hispania Sacra. 6 (1953), pp. 231-240.

Casado, D. (2003). Beneficencia. Barcelona: Tirant lo Blanch, 2003.

Código de Derecho Canónico de 1917. (1999). Madrid: BAC, 1999.

Código de Derecho Canónico. (1992). Madrid: Trivium, 1992.

Comín F. (2010). De la beneficencia al estado del bienestar, pasando por los seguros sociales. // Revista de historia de la economía de la empresa. 4 (2010), pp. 9-18.

Fernández, S. (2007). Los orígenes de la beneficencia. Humanismo cristiano, derecho de pobres, Estado liberal.// La Razón Histórica. 1 (2007), pp. 12-30.

García, J.J. (1996). Beneficencia y sanidad en el siglo XVIII. Murcia: Universidad, 1996.

González Lozano, F. (2015). Historia pedagógica del Seminario Conciliar de San Atón. 1851-1962. Badajoz: Fundación Obra Social Caja Badajoz, 2015.

Herrera, M. (1999). Los orígenes de la intervención estatal en los problemas sociales. Madrid: Escuela Libre, 1999.

Iguacen Borau, D. (1999). Diccionario del patrimonio cultural de la Iglesia. Madrid: Encuentro, 1999.

Jiménez Salas, M. (1972). Beneficencia eclesiástica. En Aldea Vaquero, Q.; Marín Martínez, T.; Vives Gatell, J. (dirs.). Diccionario de Historia Eclesiástica. Madrid: Instituto Enrique Flórez, 1972, pp. 213-238.

Maza, E. (1987). Pobreza y asistencia social en España. Siglos XVI al XVIII. Valladolid: Universidad, 1987.

Maza, E. (1999). Pobreza y beneficencia en la España Contemporánea (1808-1936). Madrid: Ariel, 1999.

Palma, A. (2006). Administraciones públicas y protección de la infancia. Madrid: Ministerio de Administraciones Públicas, 2006.

Posada, J. (1995). Estudios sobre la beneficencia pública. Oviedo: Universidad, 1995.

Rops, D. (1973). Historia de la Iglesia. Madrid: Casal y Vall, 1973.

Rubio Merino, P. (1999). Archivística Eclesiástica: Nociones básicas. Sevilla: Guadalquivir, 1999.

Sánchez y Rubio, E. (1869). Historia de la beneficencia municipal de Madrid y medios de mejorarlo. Madrid: [s.n.], 1869.

Uribe, M. (2006). Entre la beneficencia y la asistencia pública. Cali (Colombia): Universidad Nacional, 2006.

Vergara Ciordia, J. (1996). Mentalidad cristiana y pensamiento pedagógico de la Iglesia en España. En Bartolomé Martínez, B. (coord.). Historia de la acción educadora de la Iglesia en España (499-526). Madrid, BAC, 1996.

Vives, J.L. (2000). Tratado del socorro de los pobres. Valencia: Vicent García, 2000.

Enviado: 2017-03-21. Segunda versión: 2017-09-14. Aceptado: 2017-09-14. 
